
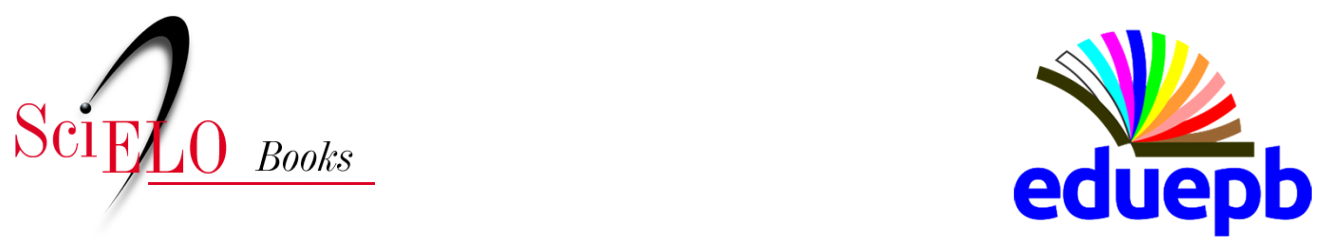

\title{
Parte IV - Comunicação, Educação e Cultura Celso Furtado, o (sub) desenvolvimento numa perspectiva cultural e a criatividade nos Maracatus Nação de Pernambuco
}

\author{
Tiago Macedo Bezerra Maia \\ João Morais de Sousa
}

\section{SciELO Books / SciELO Livros / SciELO Libros}

MAIA, T. M., and SOUSA, J. M. Celso Furtado, o (sub) desenvolvimento numa perspectiva cultural e a criatividade nos Maracatus Nação de Pernambuco. In: SOUSA, C. M., THEIS, I. M., and BARBOSA, J. L. A., eds. Celso Furtado: a esperança militante (Desafios): vol. 3 [online]. Campina Grande: EDUEPB, 2020, pp. 431-462. Projeto editorial 100 anos de Celso Furtado collection, vol. 3. ISBN: 978-65-86221-12-1.

https://doi.org/10.7476/9786586221688.0019.

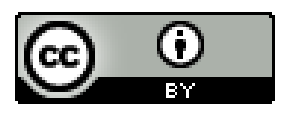

All the contents of this work, except where otherwise noted, is licensed under a Creative Commons Attribution 4.0 International license.

Todo o conteúdo deste trabalho, exceto quando houver ressalva, é publicado sob a licença Creative Commons Atribição 4.0.

Todo el contenido de esta obra, excepto donde se indique lo contrario, está bajo licencia de la licencia Creative Commons Reconocimento 4.0. 


\title{
Celso Furtado, o (sub) desenvolvimento numa perspectiva cultural e a criatividade nos Maracatus Nação de Pernambuco ${ }^{1}$
}

\author{
Tiago Macedo Bezerra Maia \\ João Morais de Sousa ${ }^{3}$
}

\begin{abstract}
[...] Lá em casa eu toco bombo feito negro fez um dia. Para replantar a semente dessa gente, gente minha. [...] Lá em cassa eu canto a história que negro viveu um dia. Pra replantar a semente dessa gente, gente minha. ("Lá em casa" - Márcio Lozano)
\end{abstract}

1 Este capítulo é mais um fruto que brota como um dos resultados parciais de uma pesquisa maior em realização pela profícua parceria de estudos e pesquisas firmada entre a Universidade Federal Rural de Pernambuco (UFRPE) e a Universidade Federal de Pernambuco (UFPE), no âmbito do Grupo de Pesquisa em Ensino de Ciências e Contemporaneidade (GECIC/DED/UFRPE/CNPq), que colabora mutuamente com o Grupo Interdisciplinar de Estudos sobre Representações Sociais e Educação (GIERSE/ CE/UFPE/CNPq). Iniciada no ano de 2017, até o ano corrente de 2020, ainda está em andamento, pois foi projetada para ter continuidade e ser concluída até o ano de 2022.

2 Professor de Filosofia, Cooperativismo/Associativismo e Educação do Campo no Instituto Federal de Pernambuco (IFPE). Mestre, bacharel e licenciado em Filosofia pela Universidade Federal de Pernambuco (UFPE). Especialista em Ensino de Filosofia pelo Espaço Contemporâneo de Ensino e Pesquisa/Faculdades Integradas de Vitória de Santo Antão (ECEP/FAINTVISA). Bacharel em Direito pela Universidade Católica de Pernambuco (UNICAP). Especialista em Direito Público pela Escola Superior da Magistratura de Pernambuco/Centro Universitário Maurício de Nassau (ESMAPE/ UNINASSAU). Especialista em Gestão Pública pela Universidade Federal Rural de Pernambuco (UFRPE). Bacharelando concluinte em Ciências Sociais na Universidade Federal Rural de Pernambuco (UFRPE). Discente pesquisador do Grupo Interdisciplinar de Estudos sobre Representações Sociais e Educação (GIERSE/CE/UFPE/CNPq), do Grupo de Pesquisa em Ensino de Ciências e Contemporaneidade (GECIC/DED/UFRPE/ CNPq), e do Grupo Teoria Crítica (DECISO/UFRPE/CNPq). (tiagombmaia6@gmail.com).

3 Professor Associado do Departamento de Ciências Sociais da Universidade Federal Rural de Pernambuco (DECISO/UFRPE) e Professor Colaborador do Programa de Pós-Graduação em Desenvolvimento Regional da Universidade Estadual da Paraíba (PPGDR/UEPB). Doutor em Sociologia pela Universidade Federal de Pernambuco (UFPE). Mestre em Ciência Política pela Universidade Federal de Pernambuco (UFPE). Bacharel em Ciências Sociais pela Universidade Federal da Paraíba (UFPB). Docente pesquisador do Grupo Interdisciplinar de Estudos sobre Representações Sociais e Educação (GIERSE/CE/UFPE/CNPq) e do Grupo de Pesquisa em Ensino de Ciências e Contemporaneidade (GECIC/DED/UFRPE/CNPq). Ex-Secretário de Turismo e Cultura de Igarassu/PE (2015-2016). (joaomsousa@uol.com.br). 


\section{Introdução}

Celso Monteiro Furtado (1920-2004), nascido paraibano na cidade de Pombal, escreveu as linhas de sua vida como pensador cosmopolita de anseios pautados numa totalidade interdisciplinar e uma erudição global de pungente atualidade. Foi também um dos maiores expoentes intelectuais brasileiros do Século XX, gozando de reconhecimento e notoriedade nacional e internacional.

Na sua vida acadêmica, formou-se Bacharel em Direito pela UFRJ e Doutor em Economia na França, pela Paris I (Sorbonne), tendo passado por Universidades de renome mundial, como, por exemplo, Yale, nos EUA e Cambridge, no Reino Unido, dentre várias outras, e, suas reflexões, seus estudos, seus escritos e até suas entrevistas ou seus discursos deixam entrever seu ímpeto de transcender as fronteiras e limites dessas disciplinas, adentrando e ousando no caminho interdisciplinar que percorreu e através do qual estabeleceu o diálogo profícuo da economia com a filosofia, a literatura, a história, a geografia e, para efeito desse capítulo, mais especificamente e em especial, com a antropologia e a sociologia, dentre as ciências sociais (BORJA, 2013).

Na sua vida pública, inserido na política institucional brasileira, esteve sempre engajado e comprometido com seu projeto de um Estado intervencionista voltado para a transformação e a mudança social necessárias para um autêntico desenvolvimento, tendo participado, em funções diversas e cargos estratégicos, por seis vezes da Gestão Pública Federal do Brasil, deixando importantes contribuições, inclusive como Ministro da Cultura entre os anos de 1986 a 1988 (BORJA, 2019; D'AGUIAR, 2012).

Homem de reflexão e ação, sempre preocupado com os problemas que formaram e nutriram toda a amplitude dos horizontes de sua visão de mundo, da pobreza nordestina de suas origens às desigualdades patentes do mundo em constante ebulição. Sempre recorrendo ao enfrentamento da realidade de seu tempo, percebeu, a partir de seu aprofundamento no engajamento consciente de uma luta contra o subdesenvolvimento e a dependência cultural e técnica que, presentes na modernização trazida pela estrutura global do capitalismo e na lógica da dominação pelo poder econômico, foram instauradas como vetor de limitação do potencial dos países periféricos subdesenvolvidos, com relação aos países capitalistas centrais desenvolvidos.

Furtado elabora então a ideia de que, com a modernização crescente e a industrialização que gradualmente proporcionou uma forçosa 
transição, no Brasil, do antigo modelo econômico primário exportador ao novo industrial modelo econômico de substituição de importações, há como pressuposto deste movimento econômico, elementos do modo de vida da burguesia que desde o início da modernidade vinha se expandindo e consolidando em todo o mundo (FURTADO, 1978).

O economista paraibano destaca, assim, o papel da cultura que pode ser entendida como um sistematizado e complexo conjunto de valores e práticas que podem permear de sentido e significado o fazer e o agir, o pensar e o sentir, pois eis que, esta surge autêntica e espontaneamente do modo de vida cotidiana compartilhada socialmente, com finalidade de concretizar na realidade os anseios de uma sociedade.

É importante ressaltar que para Furtado, a cultura, como modo de vida voltada ao âmbito dos valores-fins partilhados em uma comunidade, pareceu anteceder e preparar espiritualmente a cosmovisão refletida nos caminhos para o ensejo e estabelecimento dos meios materiais que chegam com a modernização técnica. Isso se deu, numa constatação histórica furtadiana, que se funda no importante e imprescindível esteio do $a$ priori cultural que marca a produção e a reprodução social a posteriori das estruturas que edificam as bases do poder econômico burguês advindo do capital (KORNIS, 2013).

As reflexões furtadianas sempre buscaram trazer à tona toda a densidade desveladora acessada por meio e através de um uso pioneiro e ousado de uma perspectiva conjunta, que integrou conhecimentos de diversas ciências humanas, ciências sociais e ciências sociais aplicadas, tornando assim, possível e viável, um olhar inovador e desbravador sobre a origem dos problemas do subdesenvolvimento latino-americano e brasileiro.

Diante do exposto, este capítulo objetiva, não somente elucidar os caminhos traçados por Furtado na construção de sua compreensão sobre a cultura, mas, diante disso, trazer ao debate o potencial de criatividade e resistência da cultura popular negra pernambucana (os Maracatus Nação) como uma manifestação coletiva que faz emergir espontânea e autenticamente da vida cotidiana os ideais do povo e que com seus símbolos e práticas, transmitidas de geração em geração, mantém o modo de vida e os aspectos identitários da memória e do patrimônio cultural do Brasil, fundamentais para o entendimento da formação da sociedade brasileira.

Com o exemplo dos Maracatus Nação, ícones da cultura popular de Pernambuco, que guardam nas suas toadas e nos seus baques muitos elementos da construção da sociedade e da cultura brasileiras, estes lutam 
e resistem criativamente para se manterem vivos e ativos num cenário de negligência da gestão pública em todos os seus níveis federativos.

\title{
Da cultura à interdisciplinaridade: o encontro de Celso Furtado com a antropologia
}

Ao adentrar no pensamento furtadiano, se delineia um chamado ao desbravar da complexidade do mundo por meio de sua peculiar dinamicidade interdisciplinar através da qual estabelece diálogos entre os academicamente tão diversos quanto ainda isolados campos disciplinares das humanidades, das ciências sociais e das ciências sociais aplicadas.

Para Furtado, essa nova e integradora perspectiva de ampliação das possibilidades advindas do encontro e do diálogo entre as disciplinas que iluminaram seus estudos, foram cruciais para a formulação teórica e a ação prática, ambas comprometidas sempre com seu projeto maior de transformação e emancipação da realidade das sociedades latino-americanas, iniciando com a mudança estrutural do Brasil.

E sobre o caráter interdisciplinar de seu pensamento, confirma o próprio Furtado (1997), já criticando o isolamento disciplinar da economia de sua época:

\begin{abstract}
O pesado corpo da ciência econômica, concebido para funcionar em um universo onde a dimensão tempo inexiste, oferecia grande resistência [...] Mas [...] estava sob assédio. Em torno dela pipocavam ideias novas vindas da história econômica, da demografia, da antropologia, da sociologia, da história da ciência e das técnicas. Em pouco tempo mais, cristalizaria o paradigma do desenvolvimento, e um caudal de pesquisa que se esterilizava em áreas saturadas, encontraria novo canal por onde desaguar. Ao ganhar nitidez esse paradigma, impor-se-ia a necessidade de romper fronteiras e buscar a interdisciplinaridade, de afrouxar as camisas de força, [...] de recolocar o problema epistemológico da relação entre fins e meios nas ciências sociais (FURTADO, 1997, t. 1, p. 197).
\end{abstract}

Nesse sentido, pode-se verificar, em virtude de sua perspectiva interdisciplinar, uma gama de diversas influências das mais diferentes disciplinas das ciências humanas, ciências sociais e ciências sociais aplicadas que, em conjunto, formaram e integraram a unidade de seu pensamento, por isso, pioneiro e vanguardista. Dentre esses campos disciplinares, abordaremos, a seguir, de modo sucinto, os que mais podem contribuir para os objetivos reflexivos deste capítulo. 
Das ciências sociais aplicadas, tendo estudado profundamente economia, disciplina na qual realizou seus aprofundados estudos de pósgraduação e, tendo nela se especializado, desfere contra este campo científico-disciplinar contundentes críticas em todas as suas obras, principalmente, em virtude das limitações de objetividade e metodologia enfaticamente dedutiva, e, mesmo que sempre recorrendo aos economistas clássicos como Adam Smith (1983), David Ricardo (1982) e Karl Marx (1986; 2008), (este último em especial, com mais frequência), por exemplo e, neste ponto, sempre revisita esses autores numa perspectiva próxima aos estudos de Claudio Napoleoni (1988; 2000).

Essas e outras reflexões, notada e mormente influenciaram Furtado, pela sua ideia de modo de produção, a sua crítica das formas exploratórias e de dominação e controle derivada da organização das estruturas econômicas que fundam as bases materiais e condicionam objetivamente a dinâmica cultural e política de uma sociedade dentre outros contributos marxianos; assim como esteve sempre a dialogar com economistas contemporâneos do quilate de Paul Baran (1984), e Joseph Schumpeter (1961) e, principalmente John Keynes (1992) e o seu amigo argentino Raúl Prebisch (1982), dentre outros, todos estão presentes de modo recorrente em seus escritos.

E, dessa forma, nesse diálogo econômico, contundentemente ataca os limites da economia clássica e ortodoxa, e, comentando a origem de suas ideias desenvolvimentistas, Furtado afirma que:

[...] a apreensão do fenômeno do desenvolvimento exigia um enfoque mais amplo do que nos permitia a análise econômica, pois estávamos lidando com um amplo processo de mudança cultural, "força criadora das civilizações" (FURTADO, 1997, t. 1, p. 285).

Nas suas incursões na área Sociológica, se aprofundou em autores clássicos do pensamento social tais como Max Weber $(1967 ; 1992)$ e também Karl Marx (1986; 2008), por exemplo. Com Weber (1967; 1992), pôde aprender, sob o prisma da sociologia compreensiva, a importância da ação social e de seus sentidos individuais e, nas interações sociais, os significados para a vida em sociedade.

Isso o permitiu entender que, em certas sociedades, houve fatores peculiares no modo de vida e comportamentos de seus integrantesmembros que favoreceram a consolidação e a expansão do capitalismo, e, finalmente, pôde compreender a cultura como um sistema de símbolos criados pelo homem, na vida em sociedade, e sem os quais este homem 
não vive socialmente, atrelando-se a este conteúdo simbólico-cultural que permeia de sentido o cotidiano da comunidade. Marx $(1986 ; 2008)$, como já mencionado anteriormente, foi influência marcante nas reflexões furtadianas.

Do pensamento social marxiano, recuperou suas reflexões fundamentais como, por exemplo, a ideia de estrutura social (base, infraestrutura e superestrutura), modo de produção e mudança social, dentre outros. E, o aporte teórico marxista, seja ele econômico ou sócio-político, por exemplo, foi basilar para a construção do método furtadiano chamado histórico-estrutural.

Da Teoria Crítica da Escola de Frankfurt, ao estudar Adorno (1986; 2002), Horkheimer (2002), Marcuse (1973; 1999) e Benjamin (1989), que também, como Furtado, foram dialéticos e marxistas, acolhe as suas noções de indústria cultural, da cultura de massa, da razão instrumental, padronização social unidimensional e reprodutibilidade técnica, respectivamente, do mesmo modo que as críticas e teorias da modernidade e da modernização de todos eles, por exemplo, como aporte explicativo do (i) lógico e irracional capitalismo.

E preciso aqui salientar a importante distinção que, a partir dos frankfurtianos, se estabeleceu como forma de analisar e entender a sociedade capitalista, com a diferenciação da cultura de massa, voltada para o lucro e a objetividade e a padronização em virtude do acúmulo crescente e constante do capital, diante da cultura popular, autêntica e identitária que tem como as marcas que dão sentido à tradição revisitada cotidianamente por um povo; cosmovisão, autorrepresentação, pertencimento, autenticidade e espontaneidade, tudo isto e outros elementos populares mas, inclusive opondo-se como forma de resistência em suas expressões e manifestações como resistência à mercadológica cultura capitalista.

$\mathrm{Na}$ cultura popular, haveria a singularidade que abrilhanta o sentido de cada hábito ou símbolo pela sua singularidade experienciada e vivida comunitariamente, e de forma radicalmente distinta e bastante diferenciada da reprodutibilidade de mero caráter técnico, que também caracteriza a massificação cultural em escala industrial.

Entre os sociólogos brasileiros que influenciaram Furtado, destacamse Florestan Fernandes (1972; 1975; 1976), Darcy Ribeiro (1970; 1995; 2001) e Gilberto Freyre (1957, 1969, 1990, 2010), dentre outros. É de grande valia notar que todos estes deram significativas contribuições, cada qual ao seu modo, no que se refere à busca por uma identidade e uma interpretação sócio-político-cultural do Brasil. Florestan $(1972 ; 1975 ; 1976)$ enfrentou a 
problemática da formação e consolidação de uma burguesia brasileira e também os problemas raciais inerentes ao fato do que vive o negro num país que privilegia brancos. Ribeiro (1970; 1995; 2001) procurou entender as fases socioculturais do processo civilizatório na formação da sociedade brasileira e, também, os sentidos e os significados do Brasil, para o seu povo.

Com Freyre (1957; 1969; 1990; 2010), Furtado pôde melhor adentrar na dinâmica da colonização europeia no nordeste do Brasil e a formação da sua sociedade açucareira primário-exportadora e, como nela se davam as interações sócio-políticas e econômico-culturais. Salienta-se, no entanto, que, baseado, principalmente nestes três expoentes do pensamento social brasileiro, mesmo sem essa pretensão, Furtado refuta muitas das teses de interpretação do Brasil, por exemplo, alguns pontos de Sérgio Buarque de Holanda (2006) e Raymundo Faoro (2008).

Do ponto de vista da Antropologia, talvez o prisma mais vanguardista e pioneiro de todo o arcabouço pensado por Furtado, este parece ter situado e dado à cultura e às manifestações e fenômenos culturais, um papel de destaque no processo do desenvolvimento social e econômico. Isto ocorreu, certamente, por ter estado durante um bom tempo em sua formação nos Estados Unidos da América, lugar no qual passaria uma parte importante da sua vida, de tempos em tempos, visitando, para a realização de seus estudos e a concretização de objetivos acadêmicos de pesquisa.

Em virtude disto, constata-se, em muitos aspectos de suas análises culturais, fortes influências da antropologia americana, tais como da escola antropológica difusionista cultural ou particularista histórica, de Franz Boas (1996; 2004) e, da escola antropológica interpretativa ou simbólica, de Clifford Geertz (1978; 1999; 2001). É sabido, e aqui posteriormente será melhor analisado, que Furtado concebe a cultura como um sistema de fins que articula em seu bojo um complexo de valores e símbolos que confere ao modo de vida da comunidade seu horizonte de significados e sentidos cotidianamente vividos e partilhados.

Boas (1996; 2004), fortemente baseado nas teorias alemãs do espaço vital e no culturalismo historicista, desenvolve suas ideias de difusão cultural e ciclos (círculos) de cultura. Na antropologia difusionista boasiana, há centros geográficos que concentram num dado espaço a matriz da vitalidade cultural de uma dada sociedade que, ao manifestarem seus fenômenos, irradiam e difundem essa cultura e assim expandem em ciclos temporais (circularmente/ciclicamente), ampliando no tempo-espaço os raios de influência e impacto dos rudimentos basilares deste corpo 
sociocultural, ou seja, deste modo ocorreria a difusão das culturas, tal como o nome da escola indica e pressupõe.

Um outro ponto importante para Boas $(1996 ; 2004)$ é que a construção histórica dos hábitos e práticas compartilhados na vida social, devem ser abordados em suas específicas particularidades contextuais, e daí também se deriva um dos nomes desta corrente antropológica. Salienta-se que a influência de Boas no pensamento de Furtado foi, ao mesmo tempo, introduzida e reforçada pelas leituras e estudos das teorias sociológicas e culturais de Gilberto Freyre $(1957 ; 1969 ; 1990 ; 2010)$ (que foi aluno de Boas nos EUA), e ambos estiveram notadamente presentes na construção de sua metodologia de análise e compreensão das sociedades latino-americanas e da formação social brasileira.

É possível encontrar uma nítida relevância de Freyre e da antropologia, para Furtado, desde tenra idade de adolescente, sendo anterior, inclusive, a seus estudos econômicos, como o próprio testemunha e explicita em trecho das "Aventuras de um economista brasileiro" (Cf. FURTADO, 1997, t. 2, p. 16), em que ele mesmo, corrobora com a hipótese tal como postulada e demonstrada por César Bolaño abaixo, por exemplo.

E, sendo assim, Celso Furtado:

[...] reconhece a influência [...] "norte-americana" da teoria antropológica da cultura [...] pela primeira vez por intermédio do livro de Gilberto Freyre, "Casa grande e senzala", aos 17 anos de idade, esclarecendo, não obstante, que [...] sua importância [...] revelou todo um instrumental novo de trabalho [...]. Esse instrumental novo, a teoria antropológica da cultura, estava presente, portanto, no pensamento de Furtado, desde as suas primeiras leituras, ainda na adolescência. Mais ainda, a sua ideia de cultura antecede a economia [...] (BOLAÑO, 2015, p. 93).

No âmbito da também americana antropologia interpretativa ou simbólica de Geertz (1978; 1999; 2001), que se baseia na ideia de cultura sociológico-compreensiva weberiana, Max Weber $(1967 ; 1992)$ analisa os fenômenos e manifestações culturais como redes de sentido e símbolos criados, significados compartilhados, articulados e legitimados pelas práticas e costumes, saberes e comportamentos, fazeres e hábitos, como modos de vida próprios e autênticos de uma sociedade.

Partindo disso, Geertz $(1978 ; 1999 ; 2001)$, utilizando das contundentes críticas da fenomenologia e da hermenêutica direcionadas à razão moderna e ao viés científico das teorias antropológicas clássicas que desta racionalidade derivam e se fundaram, propõe uma antropologia que não se baseia no superficial e limitado objetivismo do ímpeto científico, mas 
sim, na densidade das singularidades subjetivas que, ao interagirem socialmente, se compreendidas, podem desvelar a profundidade de uma cultura, forjada nesses hábitos e valores coletivos, como modo de vida, a cultura é tecida tal como uma obra de arte, permeando de sentido, assim, as vivências e experiências socialmente compartilhadas.

É na busca do acesso a este denso complexo de sentidos individuais e significados coletivos simbólico-social e culturalmente presentes no modo de vida comunitário, que Geertz (1978; 1999; 2001) aplica pressupostos compreensivos fenomenológico-hermenêuticos, para acender a clareira da interpretação cultural.

Em vários momentos de sua obra, Furtado faz uso de termos e construções reflexivas, no tocante às limitações metodológico-objetivas das ciências econômicas e da racionalidade científica, por exemplo, que remetem à fenomenologia e à hermenêutica, indiretamente, mas que, também, pode se admitir, por isso, que a análise furtadiana da cultura seja compreendida, num viés antropológico-interpretativo, como o das ideias de Geertz (1978; 1999; 2001).

Isto posto, no tocante ao que se compreende como interdisciplinaridade, também sob a perspectiva de Celso Furtado, pode-se pontuar que:

A palavra interdisciplinaridade refere um modo de trabalhar o conhecimento [...] orientado pela reintegração dos aspectos que ficaram isolados ou dispersos em razão de certo tratamento dito disciplinar. $\mathrm{O}$ que se busca com esse expediente [...] é justamente uma visão não fragmentada, ampla e por isso mesmo mais adequada à realidade [...]. Em suma, a interdisciplinaridade busca compensar a fragmentação do saber que decorre não da realidade, mais dos meios que dispomos para conhecê-la. Em última análise, o que a interdisciplinaridade busca recompor [...] é a própria realidade em sua irredutível complexidade (OLIVEIRA, 2018, p.198).

Neste sentido e por tudo isso, no esteio compreensivo da sociedade e cultura brasileiras, Furtado pode ser considerado, também, um dos grandes intelectuais intérpretes do Brasil do século XX, e, com certeza, podese dizer que ele é um dos expoentes do chamado "pensamento social brasileiro".

Após se revisitar e reconstruir um pouco do caminho e da influência do conhecimento antropológico sobre a cultura e as suas correntes americanas na perspectiva interdisciplinar do pensamento furtadiano, bem como se resgatar de modo sucinto, também, como se deu o legado da antropologia e sua recepção em Furtado, o próximo tópico analisará uma 
de suas grandes contribuições para as ciências sociais e sociais aplicadas, o método histórico-estrutural, situando a cultura, a partir deste, no prisma do estruturalismo latino-americano.

\section{O método histórico-estrutural de Celso Furtado: um novo suporte para os estudos do (sub)desenvolvimento no estruturalismo latino-americano}

É importante salientar aqui que mesmo no tópico anterior tendo sido elencadas algumas das mais importantes influências formativas interdisciplinares do pensamento de Furtado, com menção especial à antropologia e à sociologia, dentre diversas outras que, neste texto, não foram mencionadas, articulam-se estas inspirações numa perspectiva de integração e diálogo interdisciplinar.

Celso Furtado, com todas as disciplinas (campos científico-disciplinares) que estavam em seu horizonte, delas muito recepcionou de modo a estabelecer um frutífero diálogo entre as mesmas, mas, sempre tecendo contundentes críticas a essas, ou seja, não apenas reproduziu ideias na construção de suas teorias e métodos, mas, ao recebê-las, as articulou de um modo peculiar e próprio no seu visionário projeto de compreensão, enfrentamento e transformação da realidade das sociedades latino americanas, com foco na mudança social, política e cultural do Brasil e seu potencial de desenvolvimento.

Sobre o prisma da interdisciplinaridade, notadamente presente na reflexão furtadiana, ressalta-se ainda que:

A postura interdisciplinar se dá por meio de um diálogo que articula os olhares de diversas disciplinas. É da ordem do conhecimento lato sensu. Do conhecimento confrontado com os objetos. Acontece que os objetos não existem atomisticamente separados e isolados. Eles existem numa rede, o que os insere numa totalidade, são sempre partes de um todo. Formam uma teia de significações que se interpenetram umas nas outras. Não de forma mecânica. É por isso que se fala da complexidade do real. O real não é simples. Ao isolarmos os objetos em múltiplas ciências, estamos tentando separá-los de sua unidade no todo. O olhar de uma única ciência não esgota o conteúdo significativo de um objeto, por mais que se possa isolá-lo. Mas também não basta somar, justapondo-os, múltiplos olhares. O olhar interdisciplinar procura exatamente recompor o tecido do real, na sua complexidade, tramando os significados (SEVERINO, 2011, p.85). 
Após esse aporte interdisciplinar da formação do pensamento furtadiano, como acima exposto, agora é o momento de se explicitar, sucintamente, pontos dorsais de seu método próprio de análise e compreensão da realidade, o método chamado por ele e assim conhecido como histórico-estrutural, um dos fundamentos de um grupo (toda uma escola) de pensadores, dentre os quais Celso Furtado, que ficou conhecido como estruturalismo latino-americano.

Sobre essa metodologia furtadiana, que se orienta interdisciplinarmente, Celso Furtado:

[...] no momento da gênese do método histórico-estrutural,
o seu formulador estava empenhado justamente em defen-
der uma visão interdisciplinar do problema do desenvolvi-
mento, com ênfase na necessidade de incorporação de um
paradigma antropológico [...[ (BOLAÑO, 2015, p. 99)

Furtado, em suas análises, leva em consideração os fatores históricos, sociais políticos e culturais constitutivos das particularidades, especificidades e singularidades de uma sociedade, especialmente, das sociedades da América Latina (e por isso, foi uma grande contribuição para uma compreensão mais profunda da realidade, das nuances formadoras da sociedade brasileira). Portanto, trata-se de uma abordagem que parte do princípio de que as regiões ou países possuem suas características heterogêneas próprias e precisam ser vistos em suas especificidades políticas, sociais e culturais (RODRÍGUEZ e BURGUEÑO, 2007).

Não há um modelo econômico único que se adeque e satisfaça toda e qualquer sociedade. Cada território, cada povo, cada cultura, cada sociedade tem as singularidades que são próprias de sua formação, vive suas particularidades, possui especificidades histórico-geográficas e político-culturais.

Até o pensamento de Furtado e a difusão do estruturalismo latino-americano, as metodologias econômicas pretendiam explicar o desenvolvimento econômico de forma estritamente objetiva, causal e abstrata. Por outro lado, o método histórico-estrutural busca uma compreensão do todo, leva em consideração que o sistema econômico internacional apresenta hierarquias e assimetrias econômicas e de poder que o fundam e estruturam, focando assim, no contexto histórico de maneira específica, analisando a dinâmica dos processos econômicos no tempo e no espaço, tendo como pano de fundo e fio condutor analítico, processos sociais, políticos e culturais contextualizados (RODRÍGUEZ, 2009). 
Neste sentido, os contributos de Celso Furtado:

[...] resultam da fundamentação das análises na consideração de características particulares - que determinam e são determinadas pelas transformações históricas, econômicas e sociais (nacionais e internacionais) - e do desenvolvimento e da aplicação do método histórico-estrutural, que ao incorporar análises historicamente contingentes com dimensões não-reducionistas, não-mecanicistas e nãodeterministas, [...] uma concepção de mundo que considera mais do que fatores meramente econômicos. Ademais, cumpre destacar a contribuição original quanto à compreensão do desenvolvimento e do subdesenvolvimento na condição de processos mutuamente constituídos dentro de um mundo economicamente integrado e o papel do Estado como agente indispensável neste processo (MISSIO; JAYME JR; OREIRO, 2012, p. 28-29).

E, ainda, sobre o método histórico-estrutural de Furtado, que sustentou os pilares teóricos empíricos de suas reflexões sobre o subdesenvolvimento da América Latina (e do Brasil, consequentemente), pode-se salientar que:

A tarefa de pensar o subdesenvolvimento latino-americano, [...] exigia, por um lado, a leitura crítica da produção teórica sobre a temática do desenvolvimento nas diferentes correntes de pensamento em voga para não incorrer num particularismo excludente e, por outro, aprofundar o conhecimento empírico da realidade latino-americana, aprendendo com ela. Tinha-se muito claro que só assim seria possível ensaiar uma interpretação do subdesenvolvimento latino-americano capaz de instrumentalizar decisões práticas com o objetivo de sua superação. [...] Já estava posto àquela época que não havia, pois, como pensar o subdesenvolvimento sem esforço analítico totalizador. Era indispensável partir de uma perspectiva analítica integradora, tanto do ponto de vista dos diferentes aspectos da realidade e das distintas realidades [...] latino-americanas, como também das diferentes disciplinas das ciências sociais (SANTOS, 2011, p. 59-60).

Desta forma, reitera-se uma vez mais que, esse método furtadiano de análise histórico-estrutural, muito ajudou a fornecer as bases e a consolidar as críticas e reflexões de toda uma corrente (escola) de pensadores a ele contemporâneos e também posteriores aqui já mencionada, o estruturalismo latino-americano. Desse modo, essa nova metodologia elaborada por Furtado faz compreender que:

Um esquema analítico adequado para o estudo do desenvolvimento e do subdesenvolvimento [...] deve [...] fundar-se [...] na observação [...[ sistemática na qual o subdesenvolvimento é parte do processo histórico global de 
desenvolvimento, que tanto o subdesenvolvimento como desenvolvimento, são duas faces de um mesmo processo histórico universal; que ambos os processos são historicamente simultâneos, que estão vinculados de modo funcional, ou seja, que interatuam e se condicionam mutuamente, e que suas expressões geográficas concretas, nas quais se observam dois grandes dualismos: de um lado, a divisão do mundo entre Estados nacionais industriais, avançados, desenvolvidos, centrais, e os Estados subdesenvolvidos, atrasados, pobres, periféricos, dependentes; e por outro, a divisão dentro dos próprios Estados nacionais, em áreas, grupos sociais e atividades avançadas e modernas, e em áreas, grupos e atividades atrasadas, rudimentares e dependentes (SUNKEL; PAZ, 1970, p. 37. Tradução livre dos autores).

Isto posto, no próximo tópico deste escrito, se busca apresentar a noção de cultura, no pensamento de Celso Furtado, se evidenciando, com o uso intrínseco de seu método histórico-estrutural, a importância crucial da perspectiva cultural para a consolidação de suas críticas reflexivas e ideias de desenvolvimento e subdesenvolvimento, e sublinhando o potencial cultural como fonte potencial de criatividade e um ponto forte nos horizontes de possibilidades para a transformação social no Brasil.

\section{O lugar da cultura e seus fundamentos antropológicos no pensamento de Celso Furtado}

A relevância do pensamento de Furtado sobre a cultura está em ele refletir contextualizada e criticamente no sentido de desvelar nuances pioneiras acerca do promissor potencial criativo das autênticas e identitárias manifestações e fenômenos culturais, em especial, da cultura popular, com foco para o desenvolvimento num prisma multireferencial e interdisciplinar, como já anteriormente mencionado, e que são analisadas por ele que isso desbravou, à sua maneira, através seu método histórico-estrutural, a busca pela identidade da sociedade brasileira.

O pensar cultural furtadiano pode proporcionar, também, assim, uma compreensão mais aprofundada dos modos de vida, hábitos, costumes, práticas, saberes, tradições, valores e símbolos culturalmente partilhados que formam o Brasil, sua cultura e sua sociedade.

A cultura popular tem importância singular na sociedade contemporânea e isso tem sido visibilizado pelas buscas das comunidades em geral à procura de suas raízes referenciais e tradicionais, das ancestralidades, das memórias, de suas identidades culturais e consciência histórica (BOSI, 2000; KEIM e SILVA, 2012). 
Nesse sentido, torna-se fundamental a reflexão sobre o papel das manifestações e fenômenos culturais populares, ressaltando seu potencial criativo e identitário para o desenvolvimento econômico e social, em especial às relacionadas à resistência da cultura afro-brasileira, tão importantes para a formação econômica, social e política brasileiras, um ponto de encontro com a ideia de cultura de Furtado.

Este início do século XXI tem exigido novas demandas sociais, políticas e culturais que sejam a concretização de uma nova, criativa e emancipadora ideia de desenvolvimento. $\mathrm{O}$ fortalecimento, o fomento e a preservação das manifestações e dos fenômenos culturais populares, como um criativo movimento de resistência diante de limitadoras imposições, constantes pressões e notórias exclusões da modernização e do capitalismo (CHAUI, 1986; FREIRE, 1996; BARROS, 2008).

A preservação e valorização da cultura popular, figura, então, como uma urgência para que a sociedade brasileira atinja um estágio satisfatório, mais amplo, genuíno e pleno de independência, criatividade e desenvolvimento, também numa perspectiva furtadiana (KORNIS, 2013).

Celso Furtado, então, como economista de formação acadêmica, mas também, como um intelectual de uma vida escrita como humanista, se propõe a enfrentar o problema de identificar qual o impacto da economia na elaboração de uma reflexão sobre a cultura, e, ao mesmo tempo, explicitar qual a força criativa da raiz cultural que pode impulsionar ao pleno desenvolvimento, a América Latina, o Brasil.

O pensamento furtadiano sobre os aspectos culturais, se elabora então, refletindo sobre os contextos em que o diálogo cultura-economia pode ser verificado no fluxo do tempo e na dinâmica do espaço. Assim, se desvela e elenca o potencial cultural, ponto crucial eivado de possibilidades de impactos diversos, também, sobre a construção das pressuposições sobre as quais se edificarão os pilares de mais viáveis e mais novos modelos econômicos que considerem esses parâmetros culturais. Furtado procura, de tal modo, realocar as temáticas da cultura, retirando -as da periferia na modelagem econômica, e, dando-a visibilidade sob o prisma da economia, para alçá-la à centralidade nos debates sobre o (sub) desenvolvimento (KORNIS, 2013).

Neste ponto crucial, figurará como protagonista e fio condutor o aporte antropológico que sai à frente da economia, e, por isso, tão defendido e apreciado em muitas das obras de Furtado, que categoricamente declara: “[...] posto que o subdesenvolvimento é uma manifestação cultural, era natural que antropólogos nos houvessem antecipado no terreno 
que agora explorávamos, não sendo pouco o que com eles tínhamos que aprender" (FURTADO, 1997, t. 1, p. 194).

Diante do polissêmico termo cultura, no ínterim das ciências humanas, sociais e sociais aplicadas, pode-se verificar que um dos seus mais notórios sentidos é o que a coloca como elemento que distingue o que é natural (disposto e dado na realidade pela natureza) e do homem (construído inventivamente e elaborado criativamente pelo ser humano, de modo situado no tempo e no espaço, para solução de seus problemas cotidianos e para atender suas necessidades sociais) - note-se aqui uma ênfase no potencial criativo e inventivo da vida em sociedade.

Mas, notou e explicitou Furtado, como argumento-base em muitas de suas obras, que a economia, em geral, em grande parte de sua história como ciência, desconsiderou as manifestações e os fenômenos culturais, deixando a cultura fora de sua objetividade analítica, e, a cultura assim, era relegada e excluída como fator/variável de impacto/análise. Desse modo, a economia buscou adequar e limitar o rico e ilimitado manancial da cultura e sua gama de possibilidades compreensivas, impondo ao âmbito cultural apenas e superficialmente modelos objetiva, quantificada, racional e utilitariamente (MIGUEZ, MACHADO, 2010; SILVA, 2007).

É muito importante, assim, para essa nova, mas ainda tímida perspectiva dentro da economia que se volta para a visualização da ideia que, de fato, as relações econômicas condicionam e são condicionadas, em simultâneo, pela cultura como modo de vida, no mundo capitalista da civilização industrial.

O conceito primeiro de cultura deriva etimologicamente da natureza. Sua acepção arcaica significa cultivo, colheita, lavoura, agricultura. Seu sentido é relativo ao cultivo das plantas, da terra. Esta definição abarca duplamente os significados de atividade/plantar e de passividade/esperar pela natureza. Deste modo, afirma-se que:

[...] de um ponto de vista etimológico cultura é um conceito que deriva da natureza. [...] Derivamos, assim, a palavra que utilizamos para descrever as [...] atividades humanas, do trabalho e da agricultura, das colheitas e do cultivo. [...] "cultura" designava um minucioso processo material, o qual veio a ser metaforicamente transposto para os assuntos do espírito. [...] A palavra cartografa, assim, no âmbito do seu desdobramento semântico, a própria transição da humanidade de uma existência rural para uma existência urbana [...] (EAGLETON, 2003, p. 11-12). 
No século XVI, o termo cultura foi tomado, em francês, ao que parece, para dizer os processos materiais de desenvolvimento humano, suas faculdades e realizações (CUCHE, 1999). Com o seguir da história, passa de um sentido mais técnico para uma palavra alemã que abrangeria, também e principalmente, aspectos espirituais, das potencialidades do pensar humano.

Ambos os significados falam de elaborações que surgem com as experiências e vivências da vida social de uma comunidade. Então, o vocábulo cultura estava ainda preso e cerceado em adjetivos que, como atributos de sua ideia, dava sentido a ela, mas, com o passar do tempo, foi liberto dessas limitações e tomado tal como forma ou modo de abstração em si mesma (EAGLETON, 2003). Em meados do século XVIII, essa perspectiva sobre a cultura será o seu prisma fundamental de compreensão e sentido.

Assim:

A ideia de cultura vem a aparecer em meados do ano de 1871. Considera-se a mesma como uma ideação sintética de duas noções anteriormente já existentes, a alemã Kultur e francesa Civilization. A noção germânica aponta para os conteúdos espirituais e simbólicos que fundam e plasmam o pensamento e a compreensão do sentido de uma cosmovisão compartilhada em um dado grupo social. A noção francófona liga-se mais às produçỗes materiais surgidas do enfrentamento das necessidades práticas cotidianas por uma coletividade humana [...]. Edward Tylor então, em 1871, opera tal síntese na noção anglófona de Culture. Assim, Tylor consegue reelaborar e reunir numa única palavra todas as manifestações e fenômenos provenientes das realizações simbólicas e materiais do ser humano na sua vida social [...] (MAIA e SOUSA, 2019, p. 148).

E, nesse âmbito, é importante ter em mente, também, que:

Há consensos sobre o fato de que cultura é apreendida, que ela permite a adaptação humana ao seu ambiente natural, que ela é grandemente variável e que se manifesta em instituições, padrões de pensamento e objetos materiais. [...] inclui todos os elementos do legado humano maduro que foi adquirido através do seu grupo pela aprendizagem consciente, ou [...] por [...] técnicas de várias espécies, sociais ou institucionais, crenças, modos padronizados de conduta (SANTAELLA, 2003, p. 30-31).

Deste modo, as manifestações e fenômenos da cultura estão em um movimento de se construir, desconstruir e reconstruir constante e, um dos objetivos para aqueles que estudam a temática, seria desvelar tais fenômenos manifestos no mundo social tão rico de encobertos sentidos 
e significados, podendo então interpretá-los e compreendê-los. Logo, é imprescindível partir desta perspectiva, de que a cultura não é só aprendida, mas também modificada, transformada através da inovação (MELLO, 2003), com o uso das faculdades da criatividade que emergem da vida em sociedade.

A cultura parece surgir pelas necessidades próprias de cada comunidade, pelas questões enfrentadas por cada grupo social, sejam tradições passadas, elementos que se enraízam e permanecem e, ao mesmo tempo, pelos novos dinâmicos e criativos conteúdos que, ao somarem-se, trazem inovações e mudanças ao cotidiano da comunidade. A cultura, então, é "[...] um todo complexo que inclui conhecimentos, crenças, arte, moral, leis, costumes ou qualquer outra capacidade ou hábitos adquiridos pelo homem como membro de uma sociedade" (LARAIA, 1986, p. 25).

$\mathrm{Na}$ origem científica dos estudos sobre o tema, enquanto Tylor apresentou um viés etnocêntrico e unilateral da cultura das sociedades, Boas propôs novas reflexões ao sugerir uma reconstrução mais ampla, histórica e geográfica das singularidades de uma comunidade, multilateralmente, portanto. Assim, as reflexões, percepções e experimentos sobre a ciência da cultura foram, ao longo do tempo, de interesse de nomes como Edward Tylor, Franz Boas, Bronislaw Malinowski e Claude LéviStrauss, dentre outros. E desta forma se fundaram os pilares da antropologia (MAIA e SOUSA, 2019).

Ainda na primeira metade do século XX, revelou-se a crise da racionalidade e das ciências e, desta maneira as reflexões fenomenológicas e hermenêuticas, em contraposição aos postulados epistemológicos vigentes, revelaram novas, amplas e profundas possibilidades de entendimento e compreensão dos fenômenos sociais e manifestações culturais em geral.

Neste sentido, tentando superar a superficialidade da ciência e propondo uma maior densidade no entendimento das questões culturais, Max Weber (1967; 1992), com sua sociologia compreensiva, elucida as bases de sua perspectiva ao afirmar que o homem é um animal que vive preso a uma teia de significados, uma rede de sentidos criada por ele mesmo, a cultura que, também, "[...] é um sistema de símbolos e significados. [...]” (LARAIA, 1986, p. 63).

E, são justamente esses emaranhados de símbolos que, ao serem sistematizados e compartilhados ao longo do tempo e num espaço, pelos integrantes de uma comunidade, formam a cultura e dão sentido à vida social. Este é o foco principal de toda atividade interpretativa antropológica, 
o conteúdo simbólico-cultural que pode ser, assim, compreendido, interpretativamente.

Destarte:

[...] essa interpretação cultural é cabível para que se possa desvelar os sentidos originários e mais autênticos significados da cosmovisão, das tradições ancestrais e das práticas e dos saberes cotidianos de um povo, alcançando, deste modo, a densidade de uma cultura. Portanto, a atividade antropológico-interpretativa se daria como que adentrando em um texto, uma interpretação, para que se possa então compreendê-la, como uma arte, para acessar assim aos conteúdos espirituais constitutivos de sentido mais densos e assim se contrapor aos limites descritivos que a superficialidade da ciência não alcança (MAIA e SOUSA, 2019, p. 150).

Em vista da análise deste mosaico encadeado de sentidos e labirinto articulado de significados que é a cultura, Geertz (1978; 1999; 2001) ensina que se deve elucidar esses sentidos e significações latentes mais rizomáticos e ancestrais das tradições, práticas e saberes, buscando relacioná -los quando vierem a emergir, também, como horizonte de compreensão do(s) modo(s) de vida partilhado(s) pelos membros integrantes de um grupo social. Interpretar a cultura, então, é "[...] tentar ler um manuscrito estranho, desbotado, cheio de elipses, incoerências, emendas suspeitas e comentários tendenciosos [...]" (GEERTZ, 1978, p. 20).

As teias de sentido da cultura crescem e se ampliam espontaneamente e criativamente, surgem mudanças e inovações naturalmente, sem que necessariamente aqueles que a produzem percebam claramente este movimento, esta dinâmica (GEERTZ, 1978; 1999; 2001). Para Geertz (1978), a cultura emerge e desvela-se contextualmente e, apenas tendo em vista este contexto singular, pode-se buscar decifrá-la de forma autêntica, inteligível, profunda e, portanto, densamente descritiva e compreensiva.

Assim, o antropólogo norte-americano, afirma, em síntese, que:

O conceito de cultura que eu defendo, [...] é [...], como Max Weber, que o homem é um animal amarrado a teias de significados que ele mesmo teceu, assumo a cultura como sendo essas teias e sua análise; portanto, não como uma ciência experimental em busca de leis, mas como uma ciência interpretativa, à procura do significado (GEERTZ, 1978, p. 15).

É importante ressaltar aqui que, se a cultura, por um lado "se operacionaliza como elemento prático e comportamental, instrumental e simbólico de superação das dificuldades e necessidades enfrentadas no 
cotidiano da vida social" (MAIA e SOUSA, 2019, p. 151); por outro, pode ser entendida como modo de vida capaz de assinalar a distinção entre grupos sociais, entre sociedades.

Sobre isto, e também sobre o potencial e as possibilidades de criatividade e das inovações culturais, se pontua aqui que:

\begin{abstract}
Uma cultura, enquanto está sendo vivida, é sempre em parte desconhecida, em parte irrealizada. A construção de uma comunidade é sempre uma exploração, pois a consciência não pode preceder a criação, e não existe nenhuma fórmula para uma experiência desconhecida. Uma boa comunidade, uma cultura viva, irá, por causa disso, não apenas dar espaço para, mas encorajar ativamente, todo e qualquer um que possa contribuir para o avanço em consciência que é a necessidade comum... Precisamos considerar com toda a atenção qualquer afeto, qualquer valor [...] (EAGLETON, 2003, p. 168).
\end{abstract}

Mais uma vez, faz-se necessário recordar, já como anteriormente citado, que Furtado recebeu forte influência antropológica de Franz Boas (1996; 2004), através de alguns de seus alunos e discípulos, a exemplo do culturalismo, também de caráter interdisciplinar, presente nas obras sociológicas de Gilberto Freyre (1957; 1969; 1990; 2010), e nos estudos africanistas e sobre mudança social de Melville Herskovits (1963), com quem realizou trocas a partir de sua amizade, diálogo e correspondências.

Para Furtado (1974; 1978), investigar a expansão da civilização industrial burguesa europeia, ao espalhar, no mundo, seu modo e padrão de vida e consumo capitalista, é a pedra de toque da compreensão do subdesenvolvimento, entre os povos e as culturas. Neste sentido, faz-se, para ele, importante o pensamento antropológico do também americano Melville Herskovits (1963), pois:

A exemplo de outros antropólogos de sua geração, ele se inclinava a sobrepor uma 'lógica da cultura' à história, o que o levava a ver na inovação (e na descoberta) mais uma resposta do que uma mutação. Estava longe de deslizar para o determinismo cultural, mas dava ênfase à preexistência de uma 'base cultural', sem o que a inovação não seria absorvida e tampouco a mudança cultural se apresentaria ordenada. Do mesmo ponto de vista, assegurava que a difusão também seguia uma linha de menor resistência, de alinhamento com respeito à orientação preexistente. No caso de uma sociedade de classes, com cortes culturais nítidos, o processo de difusão interna de valores dar-se-ia nas mesmas linhas (FURTADO, 1997, t. 1, p. 194-195).

Percebe-se que se vive hoje, no Brasil, um momento de "resgate da contribuição de Celso Furtado sobre a cultura” (ROCHA, 2012). Deste 
modo, revisitar os textos de Furtado tem especial utilidade quando se trata de se perquirir e se questionar sobre os sentidos e significados de cultura para o subdesenvolvimento tal como marcam a América Latina e o Brasil.

\section{Os Maracatus Nação de Pernambuco: criatividade, resistência e (sub)desenvolvimento numa perspectiva cultural furtadiana}

Furtado, como já mencionado anteriormente, recebeu forte influência das concepções da antropologia de Melville Herskovits (1963) e da sociologia da cultura de Gilberto Freyre (1957, 1969, 1990, 2010), mas também é importante pontuar que nele ecoa a perspectiva de um outro autor antropólogo que também fora, por alguns anos, aluno de Franz Boas (1996; 2004), tal como os dois intelectuais antes citados: Ralph Linton (1962; 1967). Neste sentido, Linton impactou Furtado por meio de seu contato com Herskovits, que assim chegou até ele e o economista paraibano, influenciado por suas ideias afirma que: "[...] as culturas têm uma área de preocupação dominante [...] cujo estudo é essencial para a compreensão da sua dinâmica" (FURTADO, 1997, t. 1, p. 195).

Assim, Furtado acolhe a ideia acima a partir do pensamento de Linton que indica que se traduziria na religião como manifestação cultural, do mesmo modo que simbólica e dinamicamente a religiosidade expressa a cultura e isto é bem verdadeiro e tem grande notoriedade quando se analisam os povos de matriz religiosa africana (afrodescendente) e afro -brasileira, enraizadas com a vinda das nações de escravos, desde a formação colonial da sociedade brasileira. Neste período histórico, "[...] os africanos haviam sido isolados de suas matrizes culturais respectivas e, ao serem posteriormente privados das próprias línguas, perdiam o senso da identidade cultural" (FURTADO, 1984, p. 20).

Neste sentido, compreende Furtado que nas comunidades negras que foram na África escravizadas e impositivamente alocadas no Brasil pela força do colonizador europeu, foi a religião um dos aspectos fundamentais, senão o principal, de sobrevivência destes povos africanos, e modo de se manter firme e resistir diante de tantas privações e atrozes sofrimento trazidos pela escravidão. Diante disto, elucida: que "[...] numa sociedade que os reprimia e mutilava. [...], não foi por acaso que a criatividade dos negros brasileiros se refugiara na esfera religiosa" (FURTADO, 1997, t. 1, p. 195). 
Então, Furtado explicita, nesta perspectiva que:

[...] a criatividade religiosa das populações brasileiras de origem africana, estimulada em luta secular pela sobrevivência, constitui elemento fundamental na formação da nossa cultura. Por outro lado, a corrente dominante da cultura brasileira teve sua área focal crescentemente deslocada para a inovação tecnológica, principalmente através de empréstimos de outras culturas. Essa dicotomia de orientação na área de percepção mais aguda da cultura não podia ser ignorada. Para pensar o Brasil era necessário começar pela antropologia (FURTADO, 1997, t. 1, p. 195).

Por isso, uma vez mais, consoante as supracitadas palavras de Celso Furtado, fica evidenciado o porquê da escolha dos autores deste texto terem se proposto a, a partir das contribuições da antropologia, com ênfase nos elementos, manifestações e fenômenos da cultura e seus símbolos, compreender o potencial criativo cultural na centralidade que este assume no pensamento desenvolvimentista furtadiano.

Celso Furtado então explicita, tal como anteriormente já mencionado em outro tópico deste texto, apesar de não ser o seu viés mais conhecido, sempre que possível, objetivando uma abordagem mais ampla e um conhecimento mais global dos problemas da América Latina e do Brasil, uma primazia da antropologia sobre a economia, ou seja, da análise engajada da cultura sobre o mero utilitarismo reprodutivista da técnica.

Pode-se dizer assim que, "[...] a cultura é determinante na gênese dos processos e das instituições econômicas e políticas. No caso brasileiro, por exemplo, a formação cultural do nosso povo é marcada por uma assimetria fundamental [...]" (BOLAÑO, 2011, p. 7). Tal assimetria também é demarcada, portanto, na permanência e manutenção dos vínculos culturais pelos europeus brancos e, por outro lado, de um brutal afastamento baseado em rígidos impedimentos para os negros, de suas matrizes africanas.

A partir disto, se pode perceber a importância tanto das proibições das práticas religiosas como ataque a este ponto cultural de unidade das comunidades dos escravos negros africanos, para a efetiva dominação branca; quanto, por outro lado, aponta para o sublime e intrínseco sentido que a manutenção destes ritos e a resistência da religiosidade africana dos escravos, eram fundamentais para que estes suportassem o cotidiano no escravismo, e assim conseguiram compartilhar, através das práticas religiosas em suas famílias, também fracionadas pelo colonizador, a mínima 
pertença e ligação com sua ancestralidade, suas tradições originárias. Dessa forma, Furtado elucida que:

É esta uma simples enumeração das formas correntes como se exterioriza o poder. Em todas as culturas existe um segundo plano de controle, que permeia todo o processo de socialização do indivíduo e assume a forma de um sistema de valores, [...] a religião e a família, graças ao qual o custo social da repressão pode ser consideravelmente reduzido (FURTADO, 1977, p. 29).

As manifestações multifacetadas e a diversidade dos fenômenos da cultura popular brasileira, com seus símbolos de presença e resistência de variadas tradições e ancestralidades que deram origem à mesma, foram permanecendo e se consolidando, de modo criativo, desde suas raízes, conjunta e concomitantemente, cada qual da sua maneira, no fluxo do tempo histórico e na dinâmica espacial que as formaram e onde surgiram (MAIA e SOUZA, 2019).

Dentre essas manifestações da cultura popular brasileira, as de raízes africana e afro-brasileira, que surgiram a partir da chegada das nações e etnias dos negros escravizados ao Brasil, destacam-se como uma das maiores expressões das bases formadoras socioculturais do Brasil. Estas práticas e costumes ancestrais mantiveram os escravos em unidade e coesão, em virtude da pertença a memórias sociais e históricas comuns partilhadas pela negritude, mesmo quando da proibição de cultos e ritos religiosos tradicionais que, desde a sua chegada às terras brasileiras, desvelam suas criativas soluções ao enfrentarem e resistirem através do sincretismo religioso, para que este elemento cultural de especial importância, a religião, fosse mantida e tivesse sobrevida. Diante disso, então:

Mesmo proibidos de praticarem a sua religião ancestral, os
negros e negras ao longo dos séculos, recriaram de forma
criativa a sua experiência religiosa, condensando-a em uma
nova constelação simbólica de valores e sentidos funda-
mentais para a sua existência. [...] Não cabia a estes homens
e mulheres outra atitude a não ser buscar, diante da nova
realidade social, produzir coletivamente uma reinterpreta-
ção dos seus valores e símbolos (VASCONCELOS, 2001, p.
294).

Desde então até os dias de hoje, as comunidades afro-brasileiras buscam manter suas ancestrais tradições e sua identidade cultural por meio de costumes e práticas já arraigadas e manifestas na cultura popular, como é o exemplo dos Maracatus Nação de Pernambuco. 
Através desses fenômenos culturais e religiosos populares, as próprias comunidades negras pernambucanas em que se originaram experienciaram, no dia-a-dia, e celebraram, até a atualidade, na vivência coletiva destas manifestações culturais populares-religiosas. Sobre este conteúdo originário de notória religiosidade dos Maracatus Nação, sabe-se que:

O fundamento religioso manifesta-se nas formas de interpretação da cantoria, nos temas cantados e também no uso de determinados instrumentos de função ritual e cunho religioso no batuque. Pode ocorrer também o empréstimo funcional de um modo de execução próprio da cerimônia religiosa [...] que é transferida [...] para um instrumento antes profano do batuque, que passa a ser concebido, no conjunto, como detentor de reverência e obrigação religiosa (GUILLEN, 2013, p. 66).

Neste sentido, eis que mesmo hoje, para a maioria dos maracatuzeiros e maracatuzeiras, dos negros e das negras que os Maracatus Nação integram e pelas suas raízes unem-se, a cada toada e baque, cantada e tocado, estes revisitam, resgatam, revivem e recriam, com toda sua criatividade, os símbolos da resistência de suas religiões ancestrais, das lutas cotidianas e das memórias das tradições fundadas pelos seus antepassados.

Logo, compreende-se aqui porque se configura gritante e urgentemente a manutenção e o fortalecimento das manifestações culturais populares de cada local, na medida em que estas demonstram com seus movimentos de resistência e preservação criativas de suas identidades (CHAUÍ, 1986; BARROS, 2008) - tal como se enquadram os notórios casos dos Maracatus Nação.

Então, para manterem erguidos os pilares de sua cultura, isto explica e faz compreender, em termos gerais, porque os negros escravos utilizaram estratégias de criatividade, como o sincretismo religioso. Portanto, por meio do uso estrategicamente (re)criativo sincrético nas suas manifestações culturais, disfarçavam sua religião ancestral, seus cultos perseguidos e ritos proibidos em expressões correntes nas artes e/ou na religiosidade do povo e socialmente aceita dos brancos. E assim, esses fatores ocasionaram essa junção religiosa sincrética de elementos basilares africanos fundidos com imagens, figuras e faces cristãs, e disso que se originou a cultura religiosa popular afro-brasileira (VASCONCELOS, 2001).

Desta maneira, dentre outras manifestações da cultura do povo brasileiro, surgiu o Maracatu Nação, e nele reside a importância do seu conteúdo religioso como símbolo e representação social da resistência das matrizes culturais tradicionais africanas e do potencial de criatividade 
presente neste fenômeno da cultura popular pernambucana (GUILLEN, 2013; LOSSIO, 2007; MARIOSA, 2007).

Estudos atuais de diversas áreas e disciplinas das ciências humanas e sociais compreendem e confirmam em uníssono que, os Maracatus Nação:

(...) passaram por transformações e mudanças ao longo do século XX, demonstrando sua capacidade de adaptação e permanência. Trata-se, portanto, de uma forma de expressão da cultura negra, que tem sido considerada primordial na definição das identidades culturais pernambucanas, herança e resistência de negros e negras [...] (GUILLEN, 2013, p. 9).

Isto acima é citado para comprovar que os Maracatus Nação, expressão cultural popular, até alguns anos atrás, estavam estabelecidos e circulavam apenas nos limites e arredores das comunidades negras e quilombolas, por exemplo, de Pernambuco. Deste modo, foi transmitida sua identidade cultural-religiosa e suas tradições ancestrais de geração em geração, e assim resistiu e sobreviveu (re)criativamente, e, difundindo-se e legitimando-se aos poucos, expandiu os seus limites iniciais e os horizontes de seus integrantes, saindo de suas cercanias de origem. Hoje, o maracatu ultrapassa as fronteiras das comunidades afrodescendentes e cantam suas toadas e tremem seus baques, de Pernambuco para o Brasil, para toda a América Latina e para todo o mundo (MAIA e SOUSA, 2019).

Estes elementos de identidade são compartilhados não só entre seus integrantes membros, mas também pelos indivíduos todos que vivenciam, experienciam e recebem o impacto da atmosfera dessas manifestações da cultura popular, que influenciam a dinâmica da comunidade, da região onde se constituem e das áreas de interação social circunvizinhas, e em constantes conflitos contra a desagregação social e o afastamento das raízes culturais "vendidas" pela lógica do mercado, em Pernambuco.

Isto posto, é de grande valia destacar que:

[...] carnavalescos, brincantes, artistas e intelectuais trataram de legitimar uma cultura [...] autêntica [...] além de representante do modo de ser local. Em meio à afirmação de uma identidade regional, às manifestações da cultura popular foram atribuídas virtudes capazes de agregar sentimentos e emoções que congregavam os pernambucanos como um povo único (GUILLEN, 2013, p. 45-46).

Para Furtado, o legado cultural de um povo inspira o horizonte da criatividade que não se apresenta apenas como mera negação, mas sim como 
um diálogo na forma de: "[...] ato criativo [...] tanto ruptura como processo que se alimenta da herança cultural [...]" (D’AGUIAR, 2012, p. 103).

Deste modo, a criatividade:

Como ato de ruptura, [...] alimenta-se com frequência da ação de grupos contestadores que, em uma sociedade aberta, devem encontrar espaço para atuar. Demais, como a herança cultural e a criatividade se inserem na pluralidade étnica do país, o avanço na conscientização das populações negras [...] é visto como ampliação do horizonte cultural (D'AGUIAR, 2012, p. 104).

O pensamento do economista paraibano sobre as manifestações e fenômenos culturais então, permite elaborar a ideia de que a valorização das expressões da cultura popular que desvelam e trazem à tona símbolos e experiências da vida e das lutas sociais, que emergem de minorias, coletivos ou grupos à margem e/ou segregados de algum modo da sociedade, mostra as distinções presentes na realidade sócio-histórica-cultural e que apontam para a compreensão de elementos de formação de identidades e pertenças locais, regionais, nacionais, brasileiras e latino-americanas. Sobre isto:

[...] o resgate das expressões populares que constituam aspectos relevantes do cotidiano, oriundos de segmentos sociais minoritários ou marginalizados, impõe-se como decisivo para que possamos ter uma clara percepção de nossa identidade (D'AGUIAR, 2012, p. 9o).

Numa perspectiva furtadiana, é de grande valia sempre ter em mente que esta não se propõe apenas a pensar que o drama da luta pelo livre exercício da criatividade, nas comunidades negras, que em sua grande maioria, ainda se situam em áreas periféricas e vulneráveis das cidades (periferias urbanas), teria resolução com a percepção, por parte dos populares, em sua tomada de consciência da realidade que põe num injusto abismo os valores de sua produção frente aos preços em depreciação atribuídos para venda de suas produções (bens culturais) no mercado.

No pensamento de Furtado (1978) não se enseja, de modo algum, a desconsideração de estudos sobre como os diversos âmbitos culturais comportam-se e impactam economicamente, mas com a ressalva de que noções econômicas, com toda a sua limitação objetiva encerrada em modelos superficiais, não alcançam a compreensão das dimensões mais densas e profundas de uma cultura e da criatividade que lhe é intrínseca. Estes aspectos que não têm visibilidade para a ciência econômica clássica 
que nem os tangencia (a não ser instrumentalmente), são em exato o que Celso Furtado buscará evidenciar e fazer emergir com a sua noção de (sub)desenvolvimento numa perspectiva cultural, lançando assim nova luz para a necessidade do diálogo economia-antropologia, que abre horizontes, possibilidades e novos caminhos para as constatações econômicas e o pensamento social, comprometidos com a urgente transformação do Brasil.

\section{Consideracões finais}

Este capítulo procurou mostrar a evidente e notória atualidade do pensamento sociocultural elaborado pelo economista, mas também e antes de tudo, intelectual e humanista, Celso Furtado. No intuito de fazer emergir a abissal dinâmica da formação econômica e social brasileira, ilumina os passos no caminho da compreensão do subdesenvolvimento da América Latina, sempre trazendo consigo, em suas reflexões críticas, o acento da esperança no potencial de desenvolvimento socioeconômico do Brasil.

Logo, ao perseguir a totalidade e a globalidade como horizontes reflexivos, funda, no pensar interdisciplinar, os rudimentos do método histórico-estrutural que elaborou e utilizou como lente de análise de seu mundo e de seu tempo, conseguindo assim, nacional e internacionalmente, uma posição de destaque entre os expoentes do estruturalismo latino-americano.

Furtado coloca a cultura num lugar central para a compreensão do subdesenvolvimento, de modo a buscar na antropologia e na sociologia os elementos cruciais para o entendimento mais aprofundado deste processo, objetivando ultrapassar as limitadas fronteiras do pensamento econômico de sua época.

Neste sentido traz à tona, com foco no potencial criativo da cultura popular, elementos que proporcionam a compreensão dos símbolos da criativa resistência dos símbolos da religiosidade negra como base da construção identitária do Brasil. Deste modo, se procurou analisar o fenômeno cultural popular dos Maracatus Nação de Pernambuco sob esta perspectiva furtadiana da cultura.

Com isto, os resultados que aqui se encontram, apontam para a abertura de novos caminhos possíveis como contribuição para futuras e certamente vindouras pesquisas que venham a abordar o multifacetado e criativo pensamento cultural de Celso Furtado. 


\section{Referencias}

ADORNO, Theodor W. Capitalismo tardio ou Sociedade Industrial. In: COHN, Gabriel. Sociologia: Theodor Adorno. São Paulo: Ática, 1986.

BARAN, Paul A. A economia política do desenvolvimento. São Paulo: Abril Cultural, 1984.

BARROS, José Marcio. Diversidade Cultural: da proteção à promoção. Belo Horizonte: Autêntica Editora, 2008.

BENJAMIN, WALTER. Charles Baudelaire, um lírico no auge do capitalismo. São Paulo: Brasiliense, 1989.

BOAS, Franz. A Arte Primitiva. Lisboa: Fenda, 1996.

BOAS, Franz. Antropologia cultural. Rio de Janeiro: Jorge Zahar, 2004.

BOLAÑO, César Ricardo Siqueira. O conceito de cultura em Celso Furtado. Salvador: Edufba, 2015.

BOLAÑO, César Ricardo Siqueira. Indústrias criativas e os conceitos de cultura, inovação e criatividade em Celso Furtado. Políticas Culturais em Revista, 2 (4), p. 3-14, 2011.

BORJA, Bruno. Desenvolvimento e política cultural: reflexões de Celso Furtado no caminho do Ministério da Cultura. Cadernos do desenvolvimento, Rio de Janeiro, vol. 14, n. 25, p. 39-56, jul.-dez. 2019.

BORJA, Bruno. A formação da teoria do subdesenvolvimento de Celso Furtado. 2013. 202f. Tese (Doutorado em Economia Política Internacional) - Instituto de Economia, Universidade Federal do Rio de Janeiro, Rio de Janeiro, 2013.

BOSI, Ecléa. Cultura de Massa e cultura popular. 10 ed. Petrópolis: Vozes, 2000.

CHAUÍ, Marilena. Conformismo e Resistência (Aspectos da cultura popular no Brasil). São Paulo: Brasiliense, 1986.

CUCHE, Denys. A noção de cultura nas ciências sociais. trad. Viviane Ribeiro. Bauru: EDUSC, 1999. 
D'AGUIAR, Rosa Freire. (Org.) Ensaios sobre cultura e o Ministério da Cultura. Rio de Janeiro: Contraponto / Centro Internacional Celso Furtado, 2012.

D'AGUIAR, Rosa Freire. Celso Furtado e a dimensão cultural do desenvolvimento. Rio de Janeiro: E-papers / Centro Internacional Celso Furtado, 2013.

EAGLETON, Terry. A ideia de cultura. Lisboa: Ed. Temas e Debates, 2003 (Coleção Memórias do Mundo).

FAORO, Raymundo. Os donos do poder: formação do patronato político brasileiro. 4. ed. São Paulo: Globo, 2008.

FERNANDES, Florestan. O negro no mundo dos brancos. São Paulo: Difel, 1972.

FERNANDES, Florestan. Capitalismo dependente e classes sociais na América Latina. 2ª edição. Rio de Janeiro: Zahar Editores, 1975.

FERNANDES, Florestan. A revolução burguesa no Brasil. 2ª Edição. Rio de Janeiro: Zahar Editores, 1976.

FREYRE, Gilberto. Casa-grande e senzala. Lisboa: Livros do Brasil, 1957. FREYRE, Gilberto. Novo mundo nos trópicos. São Paulo: Nacional/ EDUSP, 1969.

FREYRE, Gilberto. Sobrados e mucambos. Rio de Janeiro: Record, 1990. FREYRE, Gilberto. O mundo que o português criou. São Paulo: É realizações, 2010.

FREIRE, Paulo. Pedagogia da Autonomia: saberes necessários à prática educativa. Coleção leitura. São Paulo: Paz e Terra, 1996.

FURTADO, Celso. O mito do desenvolvimento econômico. Rio de Janeiro: Paz e Terra, 1974.

FURTADO, Celso. Prefácio a Nova Economia Política. 3.ed. São Paulo: Paz e Terra, 1977.

FURTADO, Celso. Criatividade e dependência na civilização industrial. São Paulo: Círculo do Livro, 1978. 
FURTADO, Celso. Cultura e desenvolvimento em época de crise. Rio de Janeiro: Ed. Paz e Terra, 1984.

FURTADO, Celso. A fantasia organizada. In: FURTADO, Celso. Obra autobiográfica de Celso Furtado: tomo I. São Paulo: Paz e Terra, 1997.

FURTADO, Celso. Aventuras de um economista brasileiro. In: FURTADO, Celso. Obra autobiográfica: tomo II. São Paulo: Paz e Terra, 1997.

GEERTZ, Clifford. A interpretação das culturas. Rio de Janeiro: Zahar, 1978.

GEERTZ, Clifford. O saber local: novos ensaios em antropologia interpretativa. Tradução Vera M. Joscelyne. Petrópolis: Vozes, 1999.

GEERTZ, Clifford. Nova luz sobre a antropologia. Rio de Janeiro: Jorge Zahar, 2001.

GUILLEN, Isabel Cristina Martins (Org.). Inventário cultural dos maracatus nação. Dossiê. INRC do Maracatu Nação - Inventário Nacional de Referências Culturais. Recife: Ed. Universitária da UFPE, 2013.

HERSKOVITS, Melville Jean. Antropologia cultural: man and his works. Tomo I. São Paulo: Mestre Jou, 1963.

HERSKOVITS, Melville Jean. Antropologia cultural: man and his works. Tomo Ii. São Paulo: Mestre Jou, 1963.

HOLANDA, Sérgio Buarque de. Raízes do Brasil. São Paulo: Cia. das Letras, 2006.

HORKHEIMER, Max; ADORNO, Theodor. A indústria cultural: o iluminismo como mistificação de massas. In: LIMA, Luiz Costa. Teoria da cultura de massa. São Paulo: Paz e Terra, 2002.

KEIM, Ernesto Jacob; SILVA, Carlos José. Capoeira e educação póscolonial: ancestralidade, cosmovisão e pedagogia Freiriana. 1. ed. São Paulo: Paco Editorial, 2012.

KEYNES, John Maynard. A Teoria Geral do Emprego, do Juro e da Moeda. São Paulo, Editora Atlas, 1992. 
KORNIS, George. A cultura no pensamento (e na ação) de Celso Furtado: desenvolvimento, criatividade, tradição e inovação. Novos estudos - CEBRAP, São Paulo, n. 96, p. 165-171, July 2013.

LARAIA, Roque de Barros. Cultura: um conceito antropológico. Rio de Janeiro: Zahar, 1986.

LINTON, Ralph. O Homem: uma Introdução à Antropologia. São Paulo: Martins, 1962.

LINTON, Ralph. Cultura e Personalidade. São Paulo: Mestre Jou, 1967.

LOSSIO, Rúbia Aurenívea Ribeiro; PEREIRA. César de Mendonça. A importância da valorização da cultura popular para o desenvolvimento local. Recife, 2007.

MAIA, Tiago Macêdo Bezerra; SOUSA, João Morais de. Contribuições da teoria das representações sociais e da teoria antropológica interpretativa para a compreensão dos símbolos da resistência religiosa afro-brasileira nos Maracatu Nação em Pernambuco. In: SILVA, Rejane Dias da; FREITAS, Vera Lúcia Chalegre de; SOUSA, João Morais de (Orgs.). Educação, formação docente e cultura: diálogos na perspectiva da teoria das representações sociais. Curitiba: CRV, 2019.

MARIOSA, Gilmara Santos. Memória e Representações Sociais de práticas religiosas de matriz africana. Dissertação de Mestrado, Programa de Pós-Graduação em Psicologia Social, Universidade do Estado do Rio de Janeiro, Rio de Janeiro. 2007.

MARCUSE, Herbert. A ideologia da sociedade industrial: $O$ homem unidimensional. Rio de Janeiro: Zahar, 1973.

MARCUSE, Herbert. Eros e civilização. Rio de Janeiro: LTC, 1999.

MARX, Karl. Formações econômicas pré-capitalistas. 5. ed. Rio de Janeiro: Paz e Terra,1986.

MARX, Karl. Contribuição à Crítica da Economia Política. $2^{\underline{a}}$ ed. São Paulo, Expressão Popular, 2008.

MELLO, Luiz Gonzaga de. Antropologia Cultural: iniciação, teoria e temas. 10. ed. Petrópolis: Vozes, 2003. 
MIGUEZ, Paulo; MACHADO, Ana Flávia. Estudo 45: Diversidade cultural: valorização e difusão. In: BANCO NACIONAL DE DESENVOLVIMENTO ECONÔMICO E SOCIAL; UNIVERSIDADE FEDERAL DE MINAS GERAIS. Projeto PIS: perspectivas dos investimentos sociais no Brasil. 2010. Disponível em:http://www.bndes.gov.br/SiteBNDES/export/sites/ default/bndes_pt/Galerias/Arquivos/conhe cimento/seminario/Car_ ima_NE_PauloMiguez.pdf >. Acesso em 15 abr. 2020.

MISSIO, Fabrício J.; JAYME JR, Frederico G.; OREIRO, José Luís. A tradição estruturalista em economia. 2012. Disponível em: http://joseluisoreiro.com.br/site/link/3b4c257c6943e21b64ado4a29763cb3685ea7215. pdf

NAPOLEONI, Claudio. Smith, Ricardo, Marx. 6a edição. Rio de Janeiro: Graal, 1988.

NAPOLEONI, Claudio. Curso de Economia Política. Rio de Janeiro: Graal, 2000.

OLIVEIRA, Cícero. Ensino de filosofia, formação e interdisciplinaridade. Griot: Revista de Filosofia, Amargosa/Bahia, v.17, n.1, p.193-203, junho/2018.

Prebisch, Raúl. El desarrollo económico de la América Latina y algunos de sus principales problemas. In: GURRIERI, A. La obra de Prebisch en la Cepal. México: Fondo de Cultura Económica, 1982.

RICARDO, David. Princípios de economia política e tributação, com a introdução de Piero Sraffa. Apresentação de Paul Singer. Tradução de Paulo Henrique Ribeiro Sandroni. São Paulo: Abril Cultural, 1982. (Os Economistas).

RIBEIRO, Darcy. As Américas e a Civilização Processo de formação e causas do desenvolvimento cultural desigual dos povos americanos. Rio de Janeiro: Civilização Brasileira,1970.

RIBEIRO, Darcy. O povo brasileiro: a formação e o sentido do Brasil. São Paulo: Companhia das Letras, 1995.

RIBEIRO, Darcy. O processo civilizatório. Etapas da evolução sociocultural. São Paulo: Companhia das Letras, 2001. 
ROCHA, Maria. Celso Furtado e a formação da cultura brasileira. Revista de Economía Politica de las Tecnologias de la Información y de la Comunicación, São Cristovão, v. 14, n.1, ene-abr, 2012.

RODRÍGUEZ, Octavio. O estruturalismo latino-americano. Rio de Janeiro: Civilização Brasileira, 2009.

RODRÍGUEZ, Octavio; BURGUEÑO, Óscar. Desenvolvimento e cultura: notas sobre o enfoque de Celso Furtado. In: SABOIA, J.; CARVALHO, F. C. (Orgs.). Celso Furtado e o século XXI. Rio de Janeiro: Instituto de Economia/UFRJ, 2007.

SANTAELLA, Lúcia. Cultura e artes do pós-humano: da cultura da mídia à cibercultura. São Paulo: Paulus, 2003.

SANTOS, Fábio Pádua dos. O enfoque histórico-estrutural e a crítica relegada. Textos de Economia, Florianópolis, v.14, n.1, p. 51-81, jan./jul. 2011.

SCHUMPETER, Joseph Alois. Teoria do Desenvolvimento Econômico. São Paulo: Nova Cultural, 1961.

SEVERINO, Antônio Joaquim. Do ensino da filosofia: estratégias interdisciplinares. Educação em Revista, Marília, v.12, n.1, p.81-96, Jan.-Jun., 2011.

SILVA, Frederico. Política cultural no Brasil, 2002-2006: acompanhamento e análise. In: BRASIL. Ministério da Cultura. Instituto de Economia Aplicada. Coleção cadernos de políticas culturais. Brasília: Ministério da Cultura, 2007. v. 2.

SMITH, Adam. A riqueza das nações: investigação sobre sua natureza e suas causas. São Paulo: Abril Cultural, 1983.

SUNKEL, Osvaldo; PAZ, Pedro. El subdesarrollo latinoamericano y la teoría del desarrollo. Mexíco, DF: Siglo XXI, 1970.

VASCONCELOS, Sérgio S. Douets. O sincretismo afro-católico: a solução de um trauma. In: BRANDÃO, Silvana (Org.). História das religiões no Brasil. Vol. 3. Recife: Ed. Universitária da UFPE, 2001.

WEBER, Max. A ética protestante e o espírito do capitalismo. São Paulo, Pioneira, 1967.

WEBER, Max. Metodologia das Ciências Sociais. 2 vols. São Paulo: Cortez e editora UNICAMP, 1992. 